\title{
An Observer's View of the Equatorial Ocean Currents
}

\section{Introduction}

The equator is a curious place. Despite high solar radiation that is relatively steady year-round, oceanographers know to pack a sweater when sailing there. Compared with the $28^{\circ} \mathrm{C}$ surface temperatures of the adjacent tropical waters, the eastern halves of the equatorial Pacific or Atlantic Oceans have surface temperatures up to $10^{\circ} \mathrm{C}$ colder, particularly in boreal summer months. The currents are equally odd. Prevailing easterly winds over most of the tropical Pacific and Atlantic Oceans suggest westward flowing currents. Yet, eastward currents oftentimes outweigh those flowing toward the west. Motivation for the first quantitative theory of the large scale, wind driven ocean circulation, in fact, came from observations of the Pacific North Equatorial Counter Current (NECC), an eastward surface current that flows halfway around the Earth counter to the prevailing winds.

Curiosity notwithstanding, we study these equatorial ocean circulation features because they are fundamental to the Earth's climate system and its variations. For instance, the equatorial cold tongue in the Atlantic (a band of relatively cold water centered on the equator), itself a circulation induced feature, accounts for a factor of about 1.5 increase in heat flux from the southern hemisphere to the northern hemisphere. In the Pacific, the inter-annual variations in the cold tongue temperature are the ocean's part of the El NiñoSouthern Oscillation (ENSO) which affects climate and people worldwide. It is against this backdrop of intellectual curiosity and climate relevance that the
DRIFTER OBSERVED GLOBAL OCEAN CIRCULATION at 15m DEPTH:1978-1998

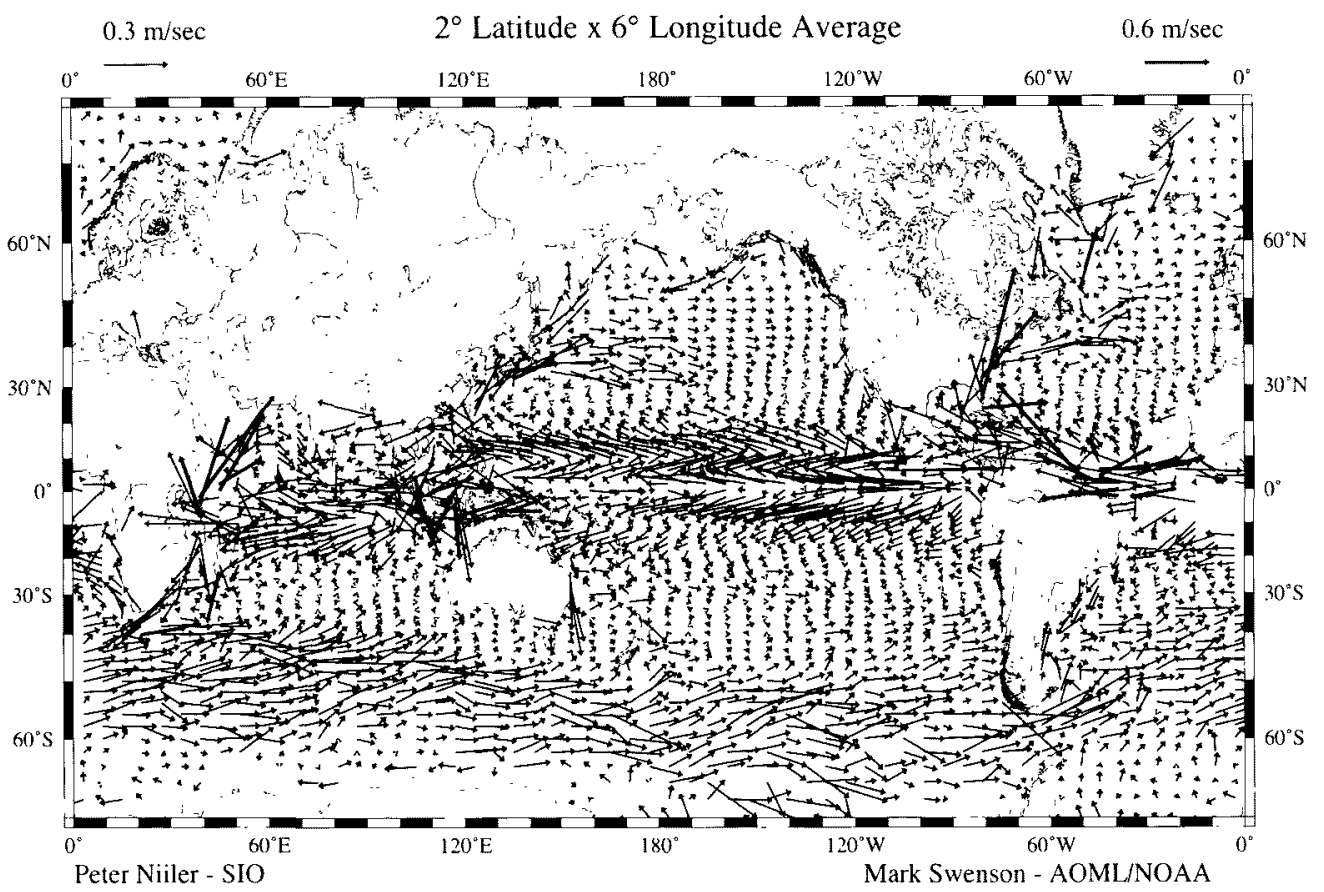

Figur 1. The surface currents of the zworld's oceans as observed with satcllite tracked drifters cusemble averaged over 2 "latitude by 6 "longitude boxes for the period 1978-1998. [From WOCE Accomplishonents, 1999 ] decades following the International Geophysical Year (IGY, 1958) experienced explosive growth in descriptions and understandings of the equatorial ocean circulation, the interactions that occur in the tropics between the ocean and the atmosphere, and the ocean's connections between the tropics and the subtropics. John Knauss played a seminal role in equatorial oceanography, both as an individual scientist exploring these strange, eastward currents and as a mentor, providing opportunity and encouragement for his graduate students and associates. The following pages describe a small portion of John's work and the questions that he raised, offer a glimpse at some of the progress made, and 
show that there is still much to be done. I apologize for the many omissions of important concepts and advances, and for the lack of references to the extensive published literature. The purpose here is to provide a conceptual overview of how the field evolved and perhaps where it is heading.

\section{The Currents of the Tropics and some of Knauss' Observations}

Maps of the ocean's surface currents are available in all oceanography textbooks. Compiled over time from ship's logs, they provide a serpentine image of liquid water movement on the Earth's surface. These ocean currents and their complementary atmospheric winds are nature's way of distributing internal energy around the Earth in adjustment for the non-uniform radiative exchanges with the solar system. The routes are complex because of the Earth's rotation and variations in water density, and they are also fully three-dimen-
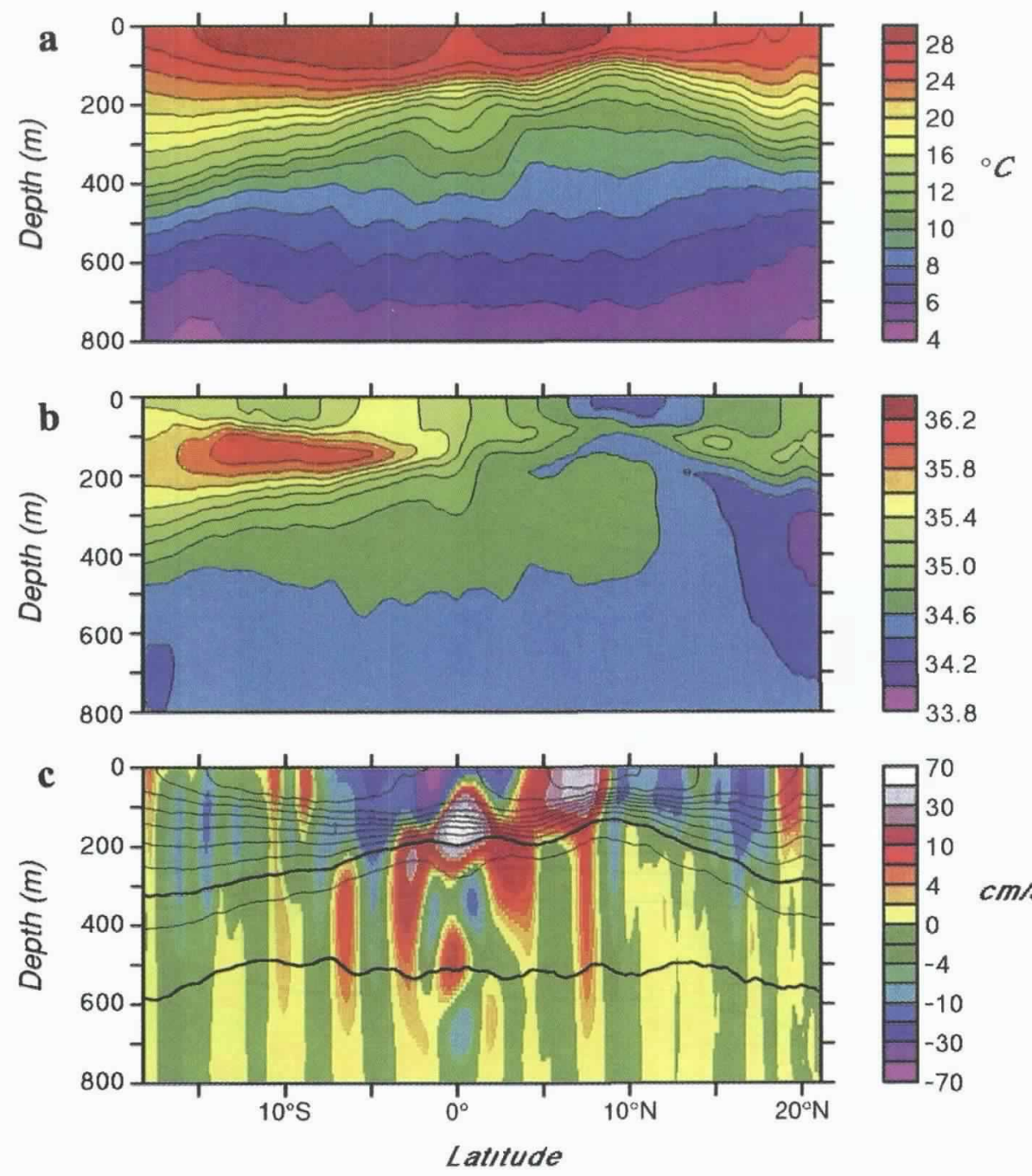

Figure 2. Meridional sections of temperature, salinity, and zonal velocity averaged from 1987-1995 using data from quarterly cruises between Fiji and Hawaii. [Plate 1 from Morris et al. ,1998.]
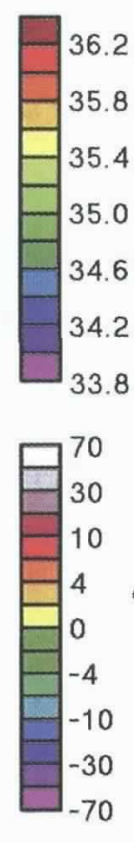

sional. Figure 1 shows a recent surface current map produced using satellite-tracked drifters. The tropics stand out as a place of relatively large and strong currents with many twists and turns. Amidst this complexity are well-organized gyres. Proceeding from south to north in either the Pacific or the Atlantic Oceans are: 1) an anti-cyclonic southern hemisphere sub-tropical gyre, 2) a clockwise equatorial gyre, 3) a cyclonic tropical gyre, and 4) an anti-cyclonic northern hemisphere sub-tropical gyre. The transition regions between these gyres are the named, zonally oriented, ocean currents: the South Equatorial Current (SEC) between the southern hemisphere sub-tropical gyre and equatorial gyre, the North Equatorial Counter Current (NECC) between the equatorial gyre and the tropical gyre, and the North Equatorial Current (NEC) between the tropical gyre and the northern hemisphere subtropical gyre. Sverdrup theory accounts for the gyres and currents in terms of the overlying wind field, the Earth's rotation, and its spherical shape. The description is incomplete, however, because the physics of the western and equatorial boundary layers are more involved.

In driving these surface currents the winds cause mass and heat flux distributions that set up the pressure field. Off the equator the pressure gradient force is balanced largely by the Coriolis effect of the currents, but within the equatorial boundary layer the pressure gradient itself tends to balance the force of the wind stress over the upper ocean. When combined with other boundary layer physics this results in subsurface eastward currents. An example of these, calculated from eight years of repeated hydrographic sections in the central Pacific, is given in Figure 2. The lower panel shows predominantly eastward flow occurring below a thin westward flowing surface veneer. Situated within about two degrees of the equator is the subsurface Equatorial Undercurrent (EUC), and just outboard of the EUC, and a little deeper, are the flanking subsurface Tsuchiya jets. These subsurface eastward currents are consequences of the equatorial boundary layer, and the 
EUC along with the surface NECC are among the many topics that John Knauss investigated. John's descriptions and analyses motivated both theoretical and experimental work that eventually fed into a new era of numerical ocean circulation modeling, a technique that was virtually non-existent at the time. Many questions still remain unanswered, particularly those regarding how the currents are linked and how they affect sea surface temperature and hence the coupled ocean-atmosphere system so vital to the Earth's climate. Let's take a look at where we are and how we got to this point.

We now recognize that the serpentine nature of the surface currents is also reflected at depth. A dynamical framework in which to describe the thermocline currents and the linkages between the subtropics and tropics was advanced in the mid-1980s by Luyten, Pedlosky, and Stommel. Their layered thermocline theory (with subsequent boundary layer modifications) makes connections between the eastward flowing subsurface equatorial currents and the mid-latitude zones of subduction. Water properties are determined at mid-latitudes in winter when the depth of the mixed layer and the density of its water are at their annual maxima. Once overlain by less dense water the subducted fluid moves slowly equatorward subject to potential vorticity conservation for individual water masses (geostrophic most of the way with relative vorticity added in the boundary layers) and the overall Sverdrup (wind stress curl) constraint for the entire thermocline. Upon arrival at the equatorial boundary layer, these thermocline waters from mid-latitudes turn eastward, accelerate, and methodically upwell and mix to form the equatorial cold tongues of the Pacific and Atlantic Oceans. Since the cold tongues are the primary source of atmospheric pressure gradients in the tropics they largely determine the tropical winds and hence the currents that respond to these winds. The combined ocean-atmosphere system therefore works through an intimate coupling between the basin-scale ocean circulation, the sea surface temperature, and the winds. Analogous to the way that zonal (i.e. East-West) changes along the equator are related to the interannual climate variations known as ENSO, meridional (i.e. North-South) changes in water mass movements produce decadal climate variations through modulations of the equatorial thermocline and ENSO. This all seems very straightforward in hindsight, but it was not so at the time of the IGY.

I will limit my attention to a few of Knauss' works, notably observations associated with the eastward flowing NECC and EUC, and I will then track the progress made through the present time. While equatorial and subtropical ocean and atmosphere scientists alike have made remarkable strides in areas not even considered at the time of the IGY, many of the same questions raised by Knauss' observations still exist, and answering these still requires observational studies.

Knauss $(1960,1966)$ are the two primary papers in which he reports on obervational studies of the Pacific EUC. The EUC discovery is attributed to Cromwell, et al. (1954) who followed up on the long line fishing vessel observations in 1951 that tackle and ship on the equator tend to drift in opposite directions (I wonder how many equatorial oceanographers will admit to their wire being tugged under the hull). The Dolphin Expedition, a multi-ship survey in boreal spring of the IGY set out to map the EUC from the central Pacific to
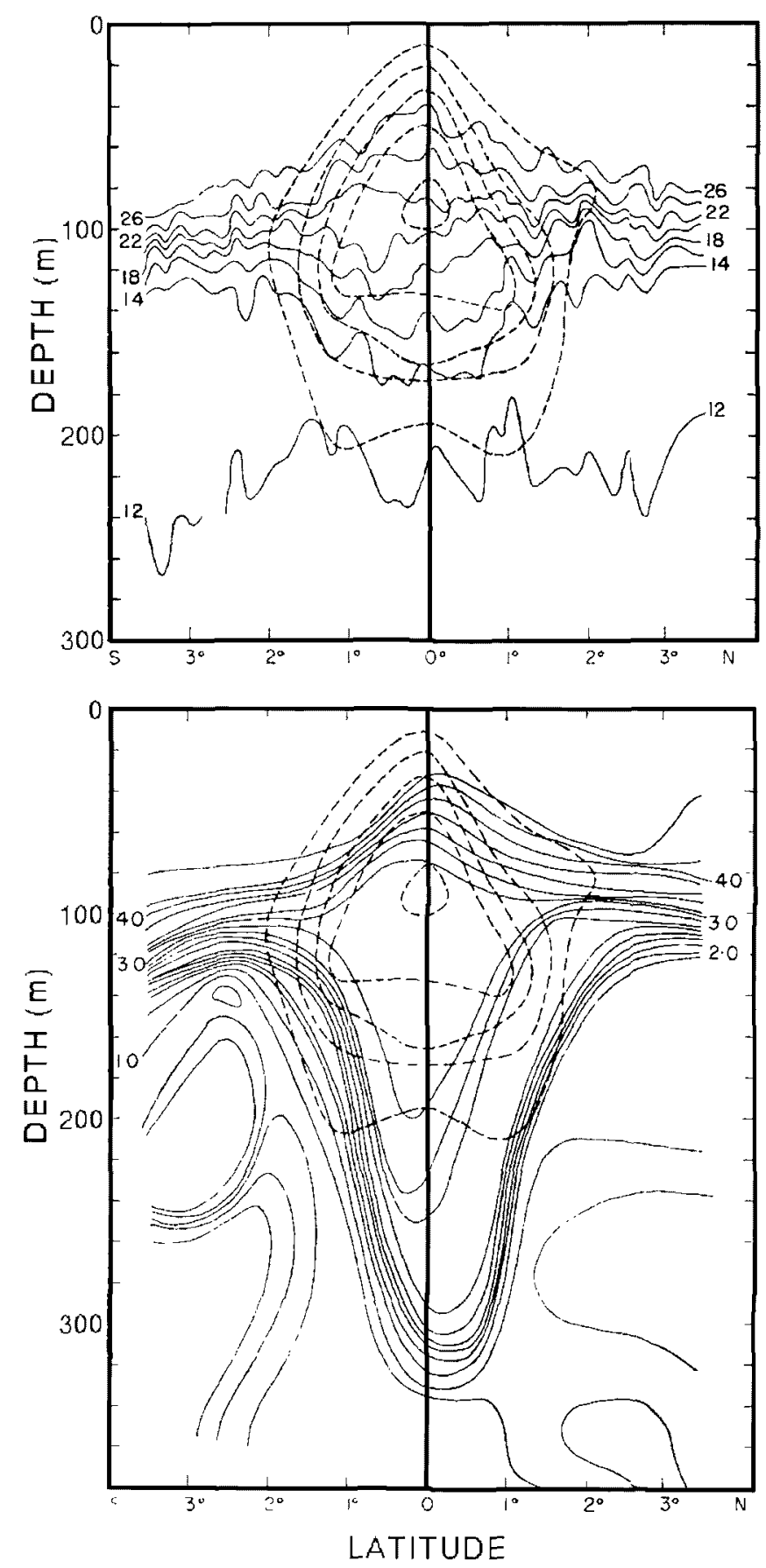

Figure 3. Zonal velocity cross section superimposed on temperature (upper panel) and oxygen (lower panel) sampled at $140^{\circ} \mathrm{W}$. [Figure 9 from Kunuss, 1960] 


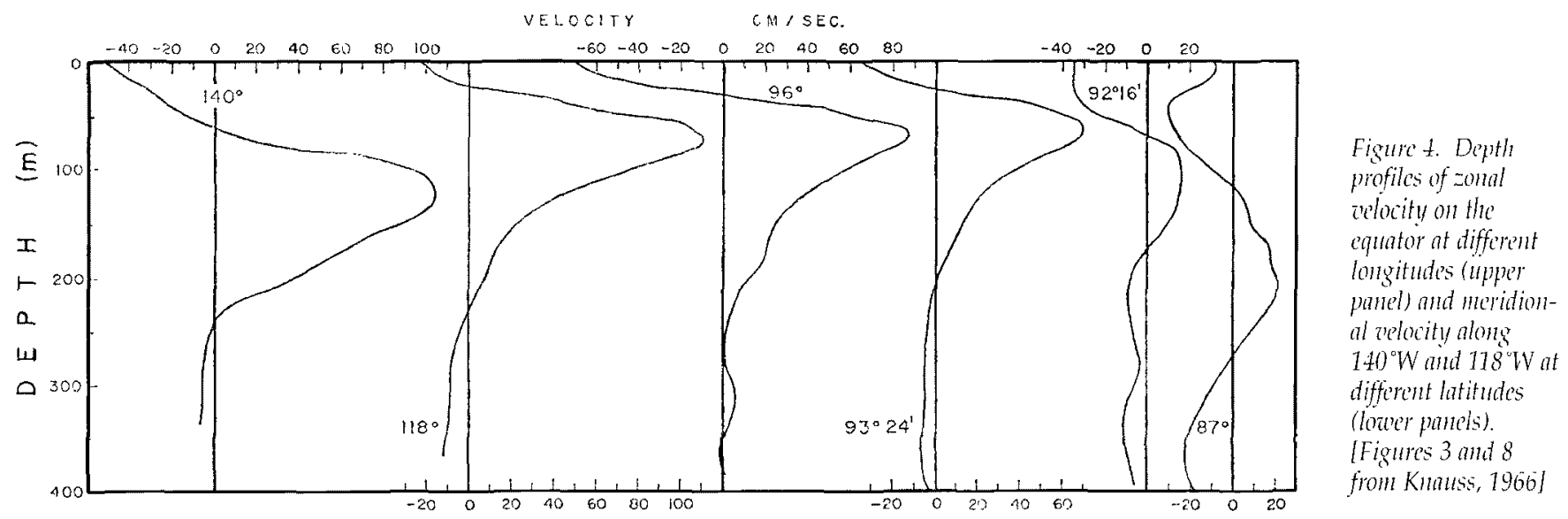

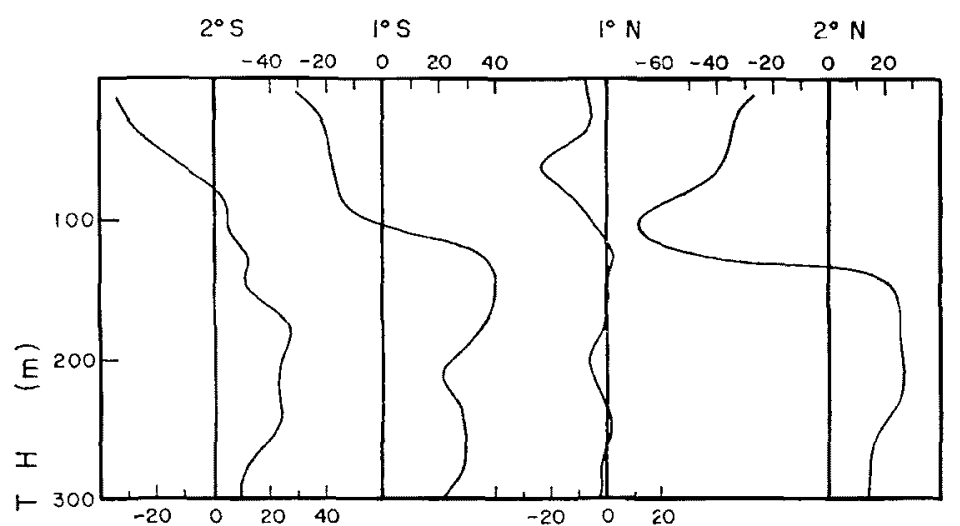

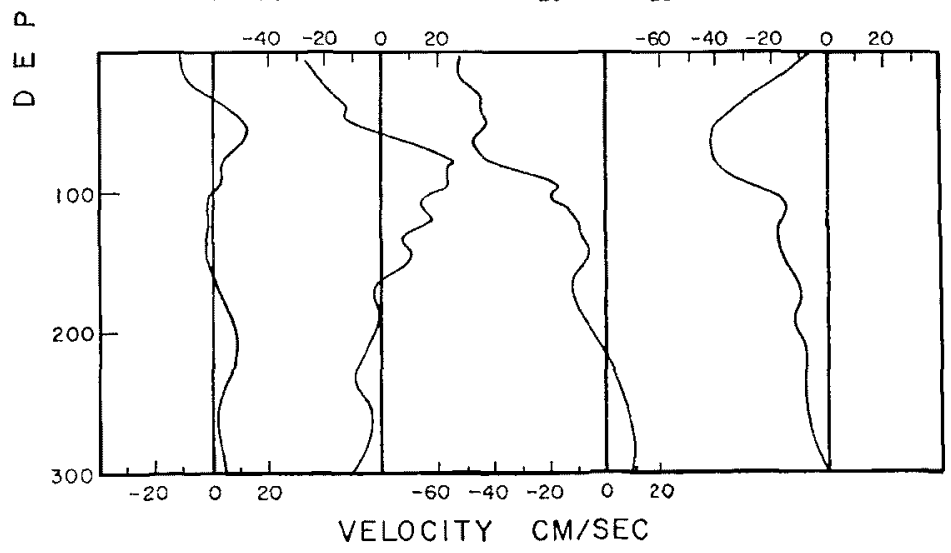

currents, such as the Gulf Stream and the Kuroshio.

The Swan Song Expedition in fall 1961 set out to further advance our understanding of the EUC and the fate of its waters as it flows past the Galapagos. Added emphasis was on the zonal and meridional divergence, as evidenced in Figure 4 (Knauss, 1966). The upper and lower panels show the zonal and meridional components of velocity at several different longitudes (along the equator) and latitudes (along $140^{\circ} \mathrm{W}$ and $118^{\circ} \mathrm{W}$ ), respectively. Zonally, we see a divergence (convergence) of fluid approximately above (below) the EUC core as the core depth shoals to the east. Meridionally, fluid appears to converge on the core while diverging near the surface. The observations imply a fully threedimensional flow field with a vertical distribution of vertical velocity that could only be speculated on. The speculations proved to be reasonable, however, and the estimates for upwelling over the upper portion of the EUC are in line with those of recent studies. The results also show that equatorial upwelling must be from relatively shallow depths.

As is usually the case new measurements

beyond the Galapagos. Knauss (1960) begins his analysis of the data collected on this expedition by stating that the Cromwell Current was unsuspected nine years earlier and not predicted then by any theories of ocean circulation. Using techniques that are very crude by today's standards the paper provides kinematical information on the three-dimensional structure, the transport, and the relationships between the velocity and hydrographic fields (Figure 3). It also provides dynamical interpretations of the EUC as a geostrophic jet and offers speculations on upwelling and mixing. The observations revealed a new current of nearly basin-scale dimension and with speeds and transports comparable to the major subtropical western boundary offer new information while at the same time clouding interpretations from previous measurements. The cloudiness here is that the EUC in fall 1961 did not have the same simple geostrophic balance as in spring 1958. Retrospectively, this began an evolving understanding on the full spectrum of equatorial current system variability. Knauss (1966) gives transport values that are half of what he found before, attributing this to a more developed SEC. Hindsight again provides understanding in terms of the annual cycle.

The demise of the EUC beyond the Galapagos is explained by the reversal of the zonal pressure gradient. Recognizing that the EUC contends well with islands farther west, Knauss argues that something else must 


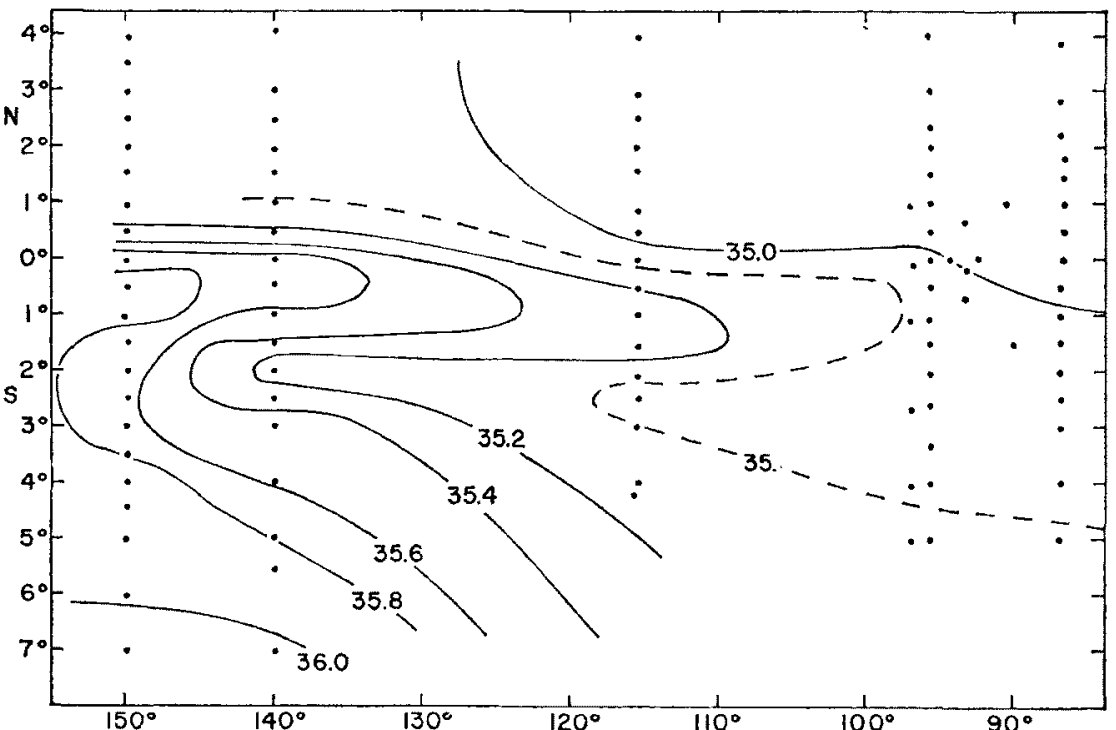

Figure 5. Isolines of maximum salinity obsered in the thermodine ooer the eastern canatorial Pacific. [Figure in from Knauss, 1966]

port variations may have resulted from tropical instability waves, annually occurring features first discovered in the Atlantic (with Knauss' involvement) some 15 years later.

Given the descriptions of the EUC (and NECC) in the Pacific (and also in the Atlantic by others) Knauss and Taft (1964) reported on similar observations from the Indian Ocean Lusiad Expedition. They found an EUC, but of lesser magnitude and with more variability in time and space than in the Pacific or Atlantic due to the different monsoon character of the Indian Ocean winds.

\section{The Evolving Base of Knowledge}

In 1974, the GARP Atlantic Tropical Experiment (GATE) brought a new generation of

be at work. Since the zonal pressure gradient (necessary to drive the EUC) goes through zero and begins to reverse sign some $1000 \mathrm{~km}$ west of the Galapagos, he argues that the islands provide the coup de grace. Among its conclusions the paper states that the next significant advance must come from the development of a realistic theoretical model, realistic enough to be tested in the field. However, testing will be difficult since any model will depend critically on the distribution of the vertical velocity component, a quantity too small to measure and that can only be deduced from continuity considerations.

Foretelling recent layered thermocline advances, Knauss (1966) also gave salinity field evidence for the pathways of water from the southern hemisphere tropics to the equator (Figure 5). He discussed how closed contours of a two-dimensional meridional section can be reconciled based on three-dimensional pathways. His description of inflow to the EUC in the central Pacific being preferentially from the southern hemisphere holds up in observations and models today.

Unlike the EUC, the NECC had long been a recognized feature of mariner's charts. It was the NECC temporal and spatial structures that were at issue at the time of the IGY. Knauss (1961) reported on three NECC cruises from 1955-1959. Largest speeds were found in the surface mixed layer with a subsurface maximum as expected by opposing wind stress. Substantial flows were also observed within and below the thermocline, and these greatly increased the transport estimates that were then available. The transports were also shown to vary substantially in time. With the observations made in boreal summer we can now surmise that the trans- oceanographers together, many of whom subsequently contributed to the evolving base of knowledge on tropical ocean-atmosphere interactions. A new framework for discussing equatorial ocean variability had been introduced by Matsuno in which the equator was recognized as a waveguide for planetary scale motions. Successful application of this theory was used to explain Pacific Island sea level variations. Moored current meter records from GATE (in which Knauss played a role) showed velocity field symmetries and structures about the equator as predicted for equatorially trapped waves. Equally interesting were the observations of meanders about the equator by the EUC and the SEC that did not conform to equatorially trapped wave theory. The GATE observations motivated a new theory for these tropical instability waves that were subsequently found to play important roles in the seasonal cycles of momentum and heat fluxes in the tropics (a book by Philander (1990) chronicles these and many other tropical ocean-atmosphere advances).

Satellite images of tropical instability waves (e.g. Figure 6) are now common for both the Atlantic and Pacific, and the waves affect transports to NECC latitudes as previously found by Knauss. Tropical instability waves occur with periods of about 3-4 weeks and wavelengths of about $1000 \mathrm{~km}$, and they are seasonally modulated. The length of the instability wave season is set in part by basin geometry through the pressure field adjustment. Hence, they last longer in the Pacific than in the Atlantic.

Currents accelerate in response to seasonally increasing winds and in the process they redistribute internal energy. Acceleration continues until the currents grow unstable, subsequently wiggling as waves, or until the 


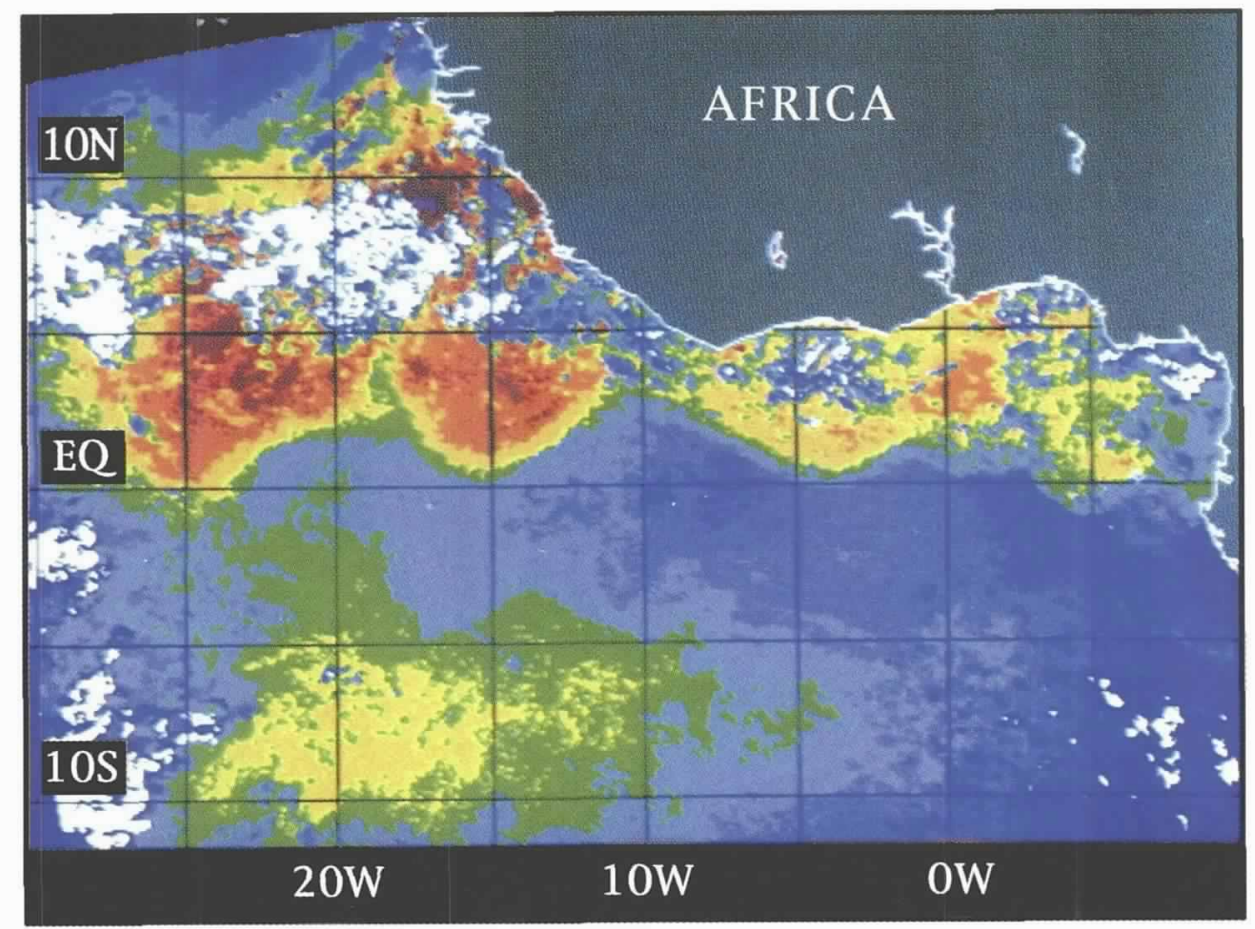

Figure 6. Tropical instability waves observed in a satellite AVHRR image of sea surface temperature from June 1983. [From the cover of Geophys. Res. Lettr., 11, August 1984, SEQUAL/FOCAL: First year results on the circulation in the equatorial Atlantic.]

and into the 1990s, and coupled ocean-atmosphere modeling in the tropics came of age. Legacies of these decades are improved data bases of all sorts, an array (TAO) of telemetering moored instruments that spans the entire equatorial Pacific (available at http://www.pmel.noaa.gov), as well as ENSO predictions and diagnostics that are published monthly (available at http://www.cpc.ncep.noaa.gov). Whereas Knauss described

pressure gradient adjusts to oppose the acceleration, thereby stabilizing the currents. When the currents wiggle they effect an equatorward transfer of momentum and internal energy that diminishes the basis for instability and warms the cold tongue. As such they act as a thermostat regulating seasonal excesses of strong velocity and temperature gradients. The waves tend to be absent or of lesser magnitude during El Niño years because the gradients are smaller. As the result of near surface current instability, energy is also radiated downward in the form of equatorially trapped Rossbygravity waves, packets of which were identified in the Atlantic.

The relatively short record length, subsurface current meter records of the 1970s provided evidence of the high frequency classes of equatorial trapped waves. Basin-scale adjustments of the equatorial thermocline, however, rely on the longer wavelength, lower frequency Kelvin and Rossby waves predicted by some theoreticians but not yet reported in the 1970s. Smiles came to some faces when the longer length, near surface observations that began in the Pacific in 1979 and then in the Atlantic in 1981 revealed Kelvin and Rossby waves. These were identified in the longer length, near surface observations that began in the Pacific in 1979 and then in the Atlantic in 1981. The excitement on inter-annual variations was invigorated by the major El Niño event of 1983. Forced equatorial long waves provided a mechanism for converting zonal wind stress variations into equatorial thermocline displacements. Observations and model studies flourished in the 1980s variability from a few short cruises, we now have records that span more than 20 years (see Journal of Geophysical Research, 103, June 1998 - The TOGA Decade: Reviewing the Progress of El Niño Research and Prediction).

While equatorial waves and ideas on tropical coupled ocean-atmosphere interactions provided stepping stones for impressive scientific advancements, these topics are generally limited to how the equatorial thermocline varies about some background mean state. Only after recognizing that not all ENSOs are alike nor predictable from a single theory did the scientific community begin looking into the connections between the subtropics and the tropics. Maturing ideas and increasing computer resources were obviously also factors. Studies of fluid pathways and the mechanisms by which fluid undergoes the changes that occur en route represent a new research thrust that will guide and challenge the present generation of ocean scientists.

Having come full circle, back to say Figure 5, we are still confronted by the conclusion of Knauss (1966) regarding theory and vertical velocity. For example, Knauss suggested several different interpretations for his observations including upwelling, downwelling, and mixing. Upwelling above the EUC core seems obvious and it has been borne out by several independent studies. The structure of the vertical velocity across and below the EUC is less obvious and more controversial. Observations during the Tropical Instability Wave Experiment show a vertical profile of vertical velocity that reverses sign from upwelling to downwelling 
below the EUC core, and a vertical profile of diapycnal vertical velocity (turbulent flux) that reverses sign from upward flux to downward flux at the EUC core. Numerical models agree on the upwelling but not on the downwelling. How do we test this? The dilemma is that subtle aspects of models such as the vertical velocity depend critically on turbulence mixing parameterizations. Models alone, so long as they depend on the parameterizations of unknown quantities, cannot solve all problems of equatorial circulation. So the need for observations is as necessary now as during the IGY. Much remains to be done; the importance of mentoring new graduate students remains as critical as ever, and the examples set by John Knauss are lessons well learned.

Mark Twain has been quoted as saying, "Adam and Eve had many advantages, but the principal one was that they escaped teething." Graduate students will never escape teething as they learn to become independent scientists, but John showed that it could be a pleasurable, exciting experience for which I close this observer's perspective on the equatorial ocean circulation with a simple statement of thanks.

\section{REFERENCES}

Cromwell, T., R.B. Montgomery and E.D. Stroup, 1954: Equatorial under-current in Pacific Ocean revealed by new methods. Science, 119, 648-649.

Knauss, J.A., 1960: Measurements of the Cromwell current. Deep-Sea Res., 6, 265-286.

Knauss, J.A., 1961: The structure of the Pacific equatorial countercurrent. J. Geophys. Res., 61, 143-155.

Knauss, J.A. and B.A. Taft, 1964: Equatorial undercurrent of the Indian Ocean. Science, 143, 354-356.

Knauss, J.A., 1966: Further measurements and observations of the Cromwell current. J. Mar. Res., 24, 205-240.

Morris, M.Y., D.H. Roemmich, G. Meyers and R.H. Weisberg, 1998: Upper Ocean heat and fresh water advection in the western Pacific Ocean. J. Geophys. Res., 103, 13023-13039.

Philander, S.G.H., 1990: El Niño, La Niña, and the Southern Oscillation. Academic Press, 289pp.

WOCE, 1999: U.S. WOCE Implementation Report Number 11. U.S. WOCE Office, College Station, TX, 28pp. D]

the leading centers of ocean research.

John was member of the Stratton Commission 19671968. One of the Commission accomplishments was to found the National Oceanic and Atmospheric Administration (NOAA), and some years later (in the tradition of the Albatross Award) John was appointed as Administrator of NOAA from 1989 - 1992. He served on various National Academy committees and recently served a term as President of the American Geophysical Union.

John is always ready to help in any capacity to further oceanography. He can be very persuasive. I vaguely remember a very noisy party by our graduate students to celebrate some oceanographic event; the police showed up and asked John and others to come along. Before they reached the police station, John had persuaded the officers that oceanography was a wonderful field, and to turn around and deliver them back to go on with their celebration.
Walter Munk Scripps Institution of Oceanography La Jolla, California USA 